\title{
Misbehavior empreendedor associado às práticas de sonegação fiscal
}

\author{
Marina emanuelli Belo ${ }^{1}$ \\ Thiago CAVAlCANTE Nascimento ${ }^{1}$ \\ ANDrÉa TORRES BarRos Batinga de MENDONÇA ${ }^{2}$
}

\author{
${ }^{1}$ Universidade Tecnológica Federal do Paraná (UTFPR) / Programa de Pós-Graduação em Administração, CURITIBA - PR, Brasil
}

2 Universidade Federal do Paraná (UFPR) / Programa de Pós-Graduação em Gestão da Informação, CURITIBA - PR, BRASIL

\begin{abstract}
Resumo
Esta pesquisa tem como objetivo compreender como se manifesta o misbehavior de empreendedores associado às práticas de sonegação fiscal em micro e pequenas empresas, sob a ótica do jeitinho brasileiro. Entende-se o conjunto de atitudes realizadas pelos membros da organização, de maneira intencional, e que resultam na violação de regras, normas e padrões sociais como misbehavior organizational. Observou-se na literatura que a formação cultural do país fortaleceu uma crença comum de que os cidadãos são constantemente prejudicados pelo sistema político, o que influencia na utilização de meios, por parte destes indivíduos, para contornar situações adversas e obter recompensas. Este mecanismo social utilizado como estratégia na solução de problemas é conhecido como jeitinho brasileiro. Assim, foi realizada uma pesquisa qualitativa com entrevistas semiestruturadas a micro e pequenos empreendedores e posteriormente a análise de conteúdo a partir de categorias de análise. Os principais resultados revelam que a sonegação fiscal é uma escolha racional do empreendedor. Embora alguns empresários tenham apresentado certa hesitação para confirmar a prática ilícita, a maior parte dos entrevistados afirmou que, ao ponderar os riscos e benefícios, o ato de sonegar é vantajoso ao pequeno negócio, uma vez que os custos com penalidades são irrisórios, considerando a baixa fiscalização.
\end{abstract}

Palavras-chave: Misbehavior. Comportamento empreendedor. Sonegação fiscal.

\section{Entrepreneurial misbehavior associated with tax evasion practices}

\begin{abstract}
This research aims to understand how entrepreneurs' misbehavior is associated with tax evasion practices in micro and small companies from the Brazilian perspective. Entrepreneurial misbehavior is understood as the set of attitudes intentionally performed by the members of the organization, which result in the violation of social rules, norms, and standards. Through a literature review, we observed that 'Brazil's cultural formation strengthened a common belief that citizens are constantly harmed by the political system, which influences these individuals to circumvent adverse situations and obtain rewards. This social mechanism used as a problem-solving strategy is known as the "Brazilian way." Thus, a qualitative research was carried out with semi-structured interviews with micro and small entrepreneurs and subsequently content analysis. The main results reveal that tax evasion is a rational choice for the entrepreneur. Although some entrepreneurs have hesitated to confirm illegal practice, most of the interviewees stated that, when considering the risks and benefits, the act of tax evasion is advantageous for small businesses since the penalties are negligible, considering the low enforcement.
\end{abstract}

Keywords: Misbehavior. Entrepreneurial behavior. Tax evasion.

\section{Misbehavior empresarial asociado con prácticas de evasión fiscal}

\section{Resumen}

Esta investigación tiene como objetivo comprender cómo la mala conducta de los empresarios se asocia con las prácticas de evasión fiscal en las micro y pequeñas empresas, desde la perspectiva del estilo brasileño. Se entiende como Misbehavior organizativo al conjunto de actitudes realizadas intencionalmente por los miembros de la organización, que resultan en la violación de reglas, normas y estándares sociales. Se observó en la literatura que la formación cultural del país fortaleció la creencia común de que los ciudadanos son constantemente perjudicados por el sistema político, lo que influye en el uso de los medios, por parte de estos individuos, para sortear situaciones adversas y obtener recompensas. Este mecanismo social utilizado como estrategia de resolución de problemas se conoce como método brasileño. Así, se realizó una investigación cualitativa con entrevistas semiestructuradas a micro y pequeños empresarios y, posteriormente, el análisis de contenido a partir de categorías de análisis. Los principales resultados revelan que la evasión fiscal es una opción racional para el empresario. Si bien algunos empresarios han dudado en confirmar la práctica ilegal, la mayoría de los entrevistados manifestó que, al considerar los riesgos y beneficios, el acto de evadir es ventajoso para las pequeñas empresas, ya que el costo de las sanciones es ínfimo, considerando la baja ejecución.

Palabras clave: Misbehavior. Comportamiento empresarial. Evasión de impuestos. 


\section{INTRODUÇÃO}

A capacidade que as empresas possuem de criar empregos, gerar renda e, consequentemente, estabelecer a arrecadação de tributos, confere-Ihes importante papel no desenvolvimento socioeconômico dos países (Eslabão \& Vechhio, 2016), entretanto, ao adotar práticas corruptas na condução de suas ações estratégicas, estas organizações passam a impactar negativamente o ambiente de negócios (Borini \& Grisi, 2009).

Embora não exista consenso na literatura quanto à definição do termo "empreendedor" e das características atribuídas a este indivíduo, é possível considerar que os empreendedores são pessoas que impulsionam o desenvolvimento das organizações, a partir da tomada de decisão baseada na identificação de novas oportunidades no ambiente de negócios, analisando as informações disponíveis e considerando os riscos dos processos (Casson, 2000; Eckhardt \& Shane, 2003; Hisrich, Peters \& Shepherd, 2014; Shane \& Venkataraman, 2000). Assim, neste trabalho, adotou-se a definição de Hisrich et al. (2014, p. 7, tradução nossa), que descrevem o empreendedor como um indivíduo que age a partir da identificação das oportunidades que surgem em ambientes de negócios que, frequentemente, são "extremamente inseguros, com altos riscos, intensas pressões de tempo" e exigem deste indivíduo "considerável investimento emocional".

De acordo com Brenkert (2009), para aproveitar as oportunidades identificadas no ambiente de negócios, o empreendedor toma decisões que podem envolver o descumprimento de regras legais e morais. Esse comportamento, na perspectiva do autor, pode ser, em determinadas situações, aceito como parte do empreendedorismo.

Dentre as práticas ilícitas adotadas por micro e pequenas empresas brasileiras, a mais utilizada é a sonegação fiscal (Forte, Domingues \& Oliveira, 2015). Como dados práticos, no Brasil, enquanto o déficit primário para o ano de 2018, de acordo com informações do Banco Central, esteve no patamar de R\$ 108 bilhões, os desvios da arrecadação prevista neste mesmo ano, representados pela sonegação fiscal, chegaram a R 570 bilhões (Sindicato Nacional dos Procuradores da Fazenda Nacional [SINPROFAZ], 2019), isto é, desconsiderando as despesas com juros da dívida pública, as contas do setor público poderiam estar em equilíbrio, caso a arrecadação tributária prevista fosse efetivamente realizada.

A sonegação fiscal, como termo adotado nesse estudo, é considerada uma prática que requer uma decisão baseada na análise racional, estratégica e cuidadosa entre os custos e benefícios relacionados ao ato corrupto, isto é, avalia-se se o retorno esperado é suficiente para compensar os riscos de detecção e punição (Allingham \& Sandmo, 1972; Clemente \& Lírio, 2017). Apesar disso, de acordo com Siqueira e Ramos (2005), a prática corrupta não é exclusivamente resultado de uma avaliação racional, pois, a decisão de sonegar também envolverá aspectos éticos e sociológicos envolvidos nas motivações individuais de cada agente.

Na perspectiva de Forte, Domingues e Oliveira (2005) a formação cultural do país fortaleceu uma crença comum de que os cidadãos são constantemente prejudicados pelo sistema político, o que influencia na utilização de meios, por parte destes indivíduos, para contornar situações adversas e obter recompensas. Este mecanismo social para solução de problemas é conhecido como jeitinho brasileiro (Duarte, 2006).

Assim, entende-se que cada empreendedor, em um processo decisório inerente a sua função, ao pensar a sonegação no âmbito organizacional, identificará os riscos e os retornos esperados com a execução de determinadas ações operacionais e estratégicas, levando em conta também os aspectos de sua formação ética individual e a situação em que se encontra no ambiente social, incluindo aspectos culturais, políticos e econômicos (Brenkert, 2009; Forte, Domingues \& Oliveira, 2015).

Considerando este contexto, foi formulada a seguinte pergunta norteadora desta pesquisa: como se manifesta o misbehavior de empreendedores associado às práticas de sonegação fiscal em micro e pequenas empresas, sob a ótica do jeitinho brasileiro?

Assim, para atender tal objetivo, esse trabalho está estruturado em seções que envolvem, além dessa introdução, o referencial teórico de base que visa discutir o comportamento empreendedor e sua relação com o conceito de Organizational Misbehavior e Jeitinho Brasileiro e a prática de sonegação fiscal. Em seguida são descritos os procedimentos metodológicos, as análises dos dados coletados, as considerações finais e as referências bibliográficas. 


\section{MISBEHAVIOR DO EMPREENDEDOR}

Durante a condução das atividades empresariais, o empreendedor enfrenta diferentes situações adversas, como a alta carga tributária, o acesso restrito ao crédito, a forte concorrência, o excesso de burocracia, entre outros. Visando aproveitar as oportunidades do ambiente de negócios, o empreendedor desenvolve estratégias organizacionais que podem envolver a burla de regras legais e morais (Brenkert, 2009; Forte et al., 2015).

O conjunto de atitudes realizadas pelos membros da organização, de maneira intencional, e que resultam na violação de regras, normas e padrões sociais é definido por Vardi e Wiener (1996) como organizational misbehavior. O termo, que é traduzido como mau comportamento organizacional, abarca três categorias, de acordo com a intenção de ação do indivíduo, o mau comportamento: a) para benefício próprio; b) para benefício da organização, e; c) para causar danos à organização.

O estudo realizado por Costa (2018) delimita que o organizational misbehavior pode ser categorizado de acordo com o direcionamento das ações realizadas pelos membros das organizações, sendo: interpessoal, intrapessoal e organizacional. A direção interpessoal ocorre quando o mau comportamento envolve, de maneira direta, ao menos duas pessoas na organização, como é o caso de situações que englobam, por exemplo, agressão e violência, assédio moral e sexual, discriminação e uso indevido de autoridade. A direção intrapessoal, por outro lado, não envolve outras pessoas além do indivíduo que expressa o comportamento desviante, como ocorre quando há o abuso de drogas ilícitas e o comportamento antissocial. Por fim, a direção organizacional expressa que o mau comportamento está relacionado diretamente com a organização, como roubo, espionagem, erros intencionais e os já citados, corrupção e fraudes (Costa, 2018). Essa, portanto, é a dimensão abordada nesta pesquisa.

Em uma recente revisão de literatura, Gervásio (2018), desenvolveu um quadro síntese, reproduzido no Quadro 1, apresentando os diferentes conceitos adotados por autores que escrevem sobre o organizational misbehavior.

\section{Quadro 1}

Revisão de conceitos para organizational misbehavior

\begin{tabular}{|c|l|}
\hline Autores & \multicolumn{1}{|c|}{ Conceitos } \\
\hline $\begin{array}{c}\text { Thompson e Ackroyd } \\
(1995, \text { p. 2) }\end{array}$ & Qualquer coisa que você faz no trabalho que não deveria fazer. \\
\hline $\begin{array}{c}\text { Robinson e Bennett } \\
(1995)\end{array}$ & $\begin{array}{l}\text { Desvios dos funcionários com comportamentos voluntários inadequados e contrários } \\
\text { aos regulamentos e normas que ameaçam o bem-estar da organização. }\end{array}$ \\
\hline $\begin{array}{c}\text { Vardi e Weitz } \\
(1996, \text { p. 153). }\end{array}$ & $\begin{array}{l}\text { Qualquer ação intencional de membros da organização que desafiam e violam (a) } \\
\text { norma e expectativas organizacionais compartilhadas e/ou (b) valores sociais, costumes } \\
\text { e padrões de conduta apropriados. }\end{array}$ \\
\hline $\begin{array}{c}\text { Collinson e Ackroyd } \\
(2005)\end{array}$ & $\begin{array}{l}\text { Está relacionado às práticas informais de subordinados e pode ser definido como } \\
\text { autoconsciência da quebra de regras. }\end{array}$ \\
\hline $\begin{array}{c}\text { Giffin e Lopez } \\
(2005)\end{array}$ & $\begin{array}{l}\text { Formas de comportamento intencional, não acidental, potencialmente prejudicial para } \\
\text { a organização ou para as pessoas na organização. }\end{array}$ \\
\hline $\begin{array}{c}\text { Medeiros e Alcadipani } \\
\text { (2016) }\end{array}$ & $\begin{array}{l}\text { Uma oposição ao comportamento organizacional como forma de resistência nas } \\
\text { organizações. }\end{array}$ \\
\hline
\end{tabular}

Fonte: Gervásio (2018).

Neste trabalho, considerando que o entendimento dos pesquisadores é semelhante ao posicionamento de Vardi e Wiener (1996), foi adotado o conceito de misbehavior organizacional destes autores em que as ações intencionais realizadas por membros da organização e que resultam na quebra de regras existem como um comportamento desviante e se configuram como um mau comportamento organizacional.

O trabalho deles estabelece que o mau comportamento organizacional pode ocorrer com intenção do membro em obter benefícios para si próprio, ou para proporcionar ganhos para a organização ou mesmo com a intenção de danificar a organização ou de prejudicar alguém. 
Entendendo que o comportamento empreendedor, seja ele positivo ou negativo, como é o caso do misbehavior, também será influenciado por fatores culturais e, considerando que os indivíduos que compõe determinada sociedade influenciam e são influenciados pela cultura local, no trabalho de Pedroso, Massukado-Nakatani e Mussi (2009) foram realizadas aproximações entre o perfil empreendedor e o jeitinho brasileiro. Os autores identificaram características comuns entre comportamento empreendedor e jeitinho, do ponto de vista positivo: habilidades para negociação e resolução de problemas, criatividade e inovação, flexibilidade e bom relacionamento pessoal.

\section{O JEITINHO BRASILEIRO}

Descrito como um fenômeno que ocorre diariamente e que pode ser visto tanto no âmbito público quanto no privado (Motta \& Alcadipani, 1999), o jeitinho brasileiro, ou simplesmente "jeitinho", é considerado o resultado da assimetria entre prática informal e racionalidade instrumental do sistema burocrático (Flach, 2012).

Conforme apresentado por Barbosa (2005, p. 44), a distinção entre o jeitinho e a corrupção é percebida pela "[...] existência ou não de alguma vantagem material advinda da situação", entretanto, há situações que, mesmo envolvendo benefícios financeiros, a ação será vista como um jeitinho e não como um comportamento corrupto. De acordo com a autora, essa diferenciação está muito associada ao valor monetário envolvido na transação: quando o nível é baixo, como no caso de gorjetas, trata-se de jeitinho, passando a ser considerado corrupção na medida que estes valores aumentam.

Motta e Alcadipani (1999) discordam deste entendimento ao afirmarem que a diferenciação da corrupção está no fato de que o jeitinho não implica ganhos materiais ao indivíduo que o concede.

Por outra perspectiva, Braga e Bezerra (2017, p. 29) argumentam que o jeitinho brasileiro estará associado à corrupção quando se materializa como uma solução desenvolvida "[...] para se evitar o cumprimento das obrigações legais, que, a despeito de serem justas ou não, estão inseridas em nosso ordenamento jurídico e devem ser observadas". Nesta visão, não é necessária a prestação de vantagens financeiras em alto valor para o jeitinho ser entendido como corrupção, para estes autores, inclusive, o jeitinho é visto como uma corrupção em processo inicial.

Assim, ao ser visto como um comportamento negativo, o jeitinho é constituído por aspectos como a transgressão de normas e leis, o desprezo às formalidades, a tendência em corromper ou ser corrompido, o baixo nível de planejamento e o não cumprimento de prazos (Barbosa, 2005; Braga \& Bezerra, 2017; Pedroso et al., 2009).

Ao avaliar os argumentos positivos do jeitinho, Pedroso et al. (2009) perceberam que há aspectos comuns entre a caracterização do jeitinho brasileiro e os atributos que formam um perfil associado aos empreendedores. Os autores encontraram na literatura selecionada as seguintes interfaces entre as características do jeitinho brasileiro e do perfil empreendedor: criatividade e inovação; iniciativa para mudança e habilidade de resolução de problemas; habilidade de persuasão e conciliação; adaptabilidade e flexibilidade e habilidade no relacionamento pessoal.

Na visão de Forte et al. (2015), durante o desenvolvimento das atividades de micro e pequenas empresas, os empreendedores enfrentam constantemente dilemas decorrentes do conflito entre a busca pela manutenção do negócio e pela maximização de resultados em função da necessidade de agir de acordo com os preceitos morais socialmente aceitos. Os autores argumentam que aspectos culturais, como o jeitinho brasileiro, somados à forte concorrência e às dificuldades para promover a sobrevivência da empresa, tendem a influenciar a decisão dos empreendedores quanto a adoção de práticas corruptas como é o caso da sonegação fiscal.

Assim, por ser uma prática social que influencia as atitudes e os comportamentos dos indivíduos no tratamento e resolução das situações adversas que se deparam nas atividades cotidianas (Vieira, Costa \& Barbosa, 1982), entende-se que o jeitinho também influenciará o comportamento dos empreendedores diante das dificuldades que podem surgir na gestão de seus negócios. 


\section{SONEGAÇÃO FISCAL EM MICRO E PEQUENAS EMPRESAS}

Dentre as práticas realizadas pelas organizações privadas classificadas como micro e pequenas empresas que desviam das expectativas sociais, a sonegação fiscal, também conhecida como evasão fiscal, é considerada uma prática corrupta e a mais comum (Borini \& Grisi, 2009; Forte et al., 2015) e ocorre a partir de uma análise que envolve aspectos racionais e éticos (Siqueira \& Ramos, 2005) e resulta em lesões ao fisco.

Correia e Pires (2017) argumentam que a insatisfação do contribuinte com o retorno social obtido por meio do pagamento dos tributos é fator preponderante ao descumprimento de normas. Neste sentido, Siqueira e Ramos (2005) defendem que, em geral, os indivíduos são avessos ao pagamento dos impostos e, dessa forma, realizam atividades a fim de reduzir suas obrigações tributárias, utilizando mecanismos que podem ser lícitos ou não. De acordo com Grzybovski e Hahn (2006) há ainda um consenso social de que o contribuinte que reduz suas obrigações tributárias, mesmo que de maneira ilícita, está agindo com mais inteligência com relação aos demais contribuintes.

Dentre as alternativas para a redução do recolhimento de tributos, a elisão fiscal é considerada uma prática lícita tendo em vista que utiliza aspectos previstos ou lacunas na legislação para o desenvolvimento de um planejamento tributário (Menezes, Wilbert \& Lima, 2017). A sonegação fiscal, em contrapartida, é vista como uma conduta ilícita em que o contribuinte utiliza de práticas como omissão de pagamento, simulação ou fraude para obter a economia tributária (Borini \& Grisi, 2009; Correia \& Pires, 2017; Lima, Wilbert \& Serrano, 2017). De acordo com G. Amaral, Olenike, L. Amaral e Steinbruch (2009), a evasão ilícita também pode ser denominada sonegação fiscal e ocorre a partir de uma ação voluntária e consciente do indivíduo que deseja reduzir, total ou parcialmente, ou postergar suas obrigações tributárias.

Dessa forma, a sonegação fiscal consiste em reduzir ou anular a carga tributária por meios ilícitos e se caracteriza como crime contra a ordem tributária com o propósito de reduzir a contribuição tributária (Berger, Dallapicula, Alencar \& Dalmácio, 2009; Borini \& Grisi, 2009; Correia \& Pires, 2017; Lima et al., 2017).

Para os empresários brasileiros, a prática de sonegação fiscal é vista como uma questão de sobrevivência do negócio, o que reduz o sentimento de ilegalidade para quem age à margem da legislação tributária, por entenderem que seus atos podem ser justificados em decorrência das dificuldades em lidar com fatores como: alta carga tributária; excesso de burocracia; má distribuição dos serviços governamentais e crescente percepção de corrupção pública, o nível de arrecadação tributária tende a cair (Correia \& Pires, 2017; Forte et al., 2015). Um estudo realizado por Correia e Pires (2017) demonstrou que, quando a contrapartida dos recursos arrecadados é considerada ineficiente ou quando o sistema fiscal é percebido como injusto, há um aumento da tolerância quanto às práticas de sonegação fiscal.

\section{MÉTODOS}

Para responder à problemática dessa pesquisa, exposta na pergunta de pesquisa "como se manifesta o misbehavior de empreendedores associado às práticas de sonegação fiscal em micro e pequenas empresas, sob a ótica do jeitinho brasileiro?", utilizou-se uma pesquisa de caráter qualitativo para compreender e explicar fenômenos sociais, observar as relações entre diferentes grupos e entender as reflexões dos agentes sobre determinadas ações (Godoi \& Bandeira-De-Mello; Silva, 2006).

A pesquisa é caracterizada também como exploratória-descritiva, pois, tem a pretensão de explorar novos elementos dentro da temática e descrever a realidade apresentada pelos entrevistados. De maneira complementar a esse entendimento, a pesquisa se valeu de entrevistas semiestruturadas com empreendedores escolhidos de maneira intencional e por acessibilidade, sendo eles, responsáveis pela criação e atual gestão de organizações classificadas pela Lei oㅡ 123/2006 como microempresas (ME) ou empresas de pequeno porte (EPP).

A escolha por micro e pequenas empresas ocorreu considerando tanto o fato do acesso aos proprietários e responsáveis por micro e pequenas empresas ser facilitado em comparação aos empreendedores de empresas de grande porte, quanto pela importância destas organizações para a economia brasileira. Como apontado no relatório Conheça os principais números sobre a participação dos pequenos negócios nas economias brasileira e paulista do Serviço de Apoio às Micro e Pequenas Empresas (SEBRAE, 2018), as micro e pequenas brasileiras são responsáveis por $27 \%$ do PIB e representam cerca de $98,5 \%$ do total de empresas privadas, ofertando $54 \%$ do total de empregos formais existentes no país. 
Quadro 2

Características dos empreendedores entrevistados

\begin{tabular}{|c|c|c|}
\hline Codinome & $\begin{array}{l}\text { Duração e } \\
\text { transcrição }\end{array}$ & Descrição do Entrevistado \\
\hline $\begin{array}{c}\text { Mercúrio } \\
\text { E1 }\end{array}$ & $\begin{array}{c}\text { Tempo: 02:39 } \\
\text { Página: } 84\end{array}$ & $\begin{array}{l}\text { Iniciou como proprietário de empresas em 1994, com a abertura de uma oficina } \\
\text { mecânica. Após quase quinze anos de atuação optou por expandir seus negócios } \\
\text { e realizou a abertura de uma transportadora para maximizar seus rendimentos. } \\
\text { Em paralelo a essas atividades realiza, de maneira informal, a compra e venda de } \\
\text { veículos usados. }\end{array}$ \\
\hline $\begin{array}{c}\text { Vênus } \\
\text { E2 }\end{array}$ & $\begin{array}{c}\text { Tempo: 01:06 } \\
\text { Página: } 30\end{array}$ & $\begin{array}{l}\text { Em } 2014 \text { investiu na compra de um minimercado e, com o passar dos anos, expandiu } \\
\text { a estrutura deste negócio. Hoje possui oito funcionários. Atualmente está com outros } \\
\text { dois negócios abertos, de maneira informal, na área de alimentação: uma casa de } \\
\text { carnes assadas e um comércio de alimentos congelados. }\end{array}$ \\
\hline $\begin{array}{l}\text { Júpiter } \\
\text { E4 }\end{array}$ & $\begin{array}{c}\text { Tempo: 00:48 } \\
\text { Página: } 24\end{array}$ & $\begin{array}{l}\text { Iniciou sua trajetória na área de informática como proprietário de uma loja no } \\
\text { interior do Paraná, entretanto, com o aumento da competitividade, a empresa } \\
\text { faliu, e o proprietário migrou para a capital como funcionário de uma organização } \\
\text { do mesmo segmento. Em } 2010 \text { voltou a empreender com a criação de uma loja de } \\
\text { venda e manutenção de equipamentos eletrônicos, prestando também consultoria } \\
\text { para algumas empresas, empregando atualmente cinco pessoas e atuando tanto } \\
\text { na gestão quanto na operação da organização. }\end{array}$ \\
\hline $\begin{array}{l}\text { Netuno } \\
\text { E6 }\end{array}$ & $\begin{array}{c}\text { Tempo: 01:28 } \\
\text { Página: } 40\end{array}$ & $\begin{array}{l}\text { Em parceria com um colega, no período da graduação, realizou a abertura de uma } \\
\text { empresa na área de desenvolvimento de softwares no ano de } 2006 \text {. Em paralelo, } \\
\text { em meados de } 2007 \text {, realizou a abertura de uma nova empresa com outro sócio e } \\
\text { no mesmo ramo de atividade, para atuar com o mercado privado. Atualmente, é } \\
\text { o único proprietário da empresa que presta serviços para o setor público e com as } \\
\text { duas empresas ativas, empregando cerca de dez funcionários. }\end{array}$ \\
\hline
\end{tabular}

Fonte: Elaborado pelos autores.

A coleta de dados ocorreu durante o mês de outubro de 2019, utilizando entrevistas semiestruturadas realizadas pelos pesquisadores, tanto presencialmente quanto por telefone, de acordo com a sugestão e disponibilidade dos entrevistados.

Após finalizar as transcrições, a organização das falas ocorreu utilizando a técnica de grade mista em que, inicialmente foram estabelecidas categorias a partir da teoria e posteriormente, conforme aspectos identificados durante a aproximação com o campo, novas categorias foram delimitadas, a saber: legitimação da sonegação fiscal; maximização dos rendimentos e sobrevivência da organização; fiscalização e probabilidade de punição; conscientização tributária, e; jeitinho brasileiro.

Assim, seguindo essas considerações metodológicas, a próxima seção explora e descreve a análise dos dados coletados. 


\section{ANÁLISE E DESCRIÇÃO DAS ENTREVISTAS}

A seguir tem-se a descrição das categorias de análise definidas na metodologia e a discussão dos casos abordados nesse estudo.

\section{Legitimação da sonegação fiscal}

De acordo com Grzybovski e Hahn (2006), os principais fatores utilizados para tentar tornar os atos de sonegação fiscal legítimos estão relacionados à burocracia dos processos governamentais e à sensação de baixo retorno social proveniente da arrecadação tributária. Além destes fatos, outro aspecto de destaque na busca por legitimação destes atos ilícitos é a alta percepção de casos de corrupção pública.

Esses fatores podem ser percebidos na fala de Vênus como justificativa para o encerramento das atividades empresariais, em que para o entrevistado há um somatório de fatores que levam, em muitos casos, à prática de sonegação fiscal, fechamento de empresas e intensificação da informalidade dos pequenos empreendimentos.

Para o entrevistado, as questões burocráticas atrapalham bastante o dia a dia do proprietário de pequenos negócios, uma vez que esse empreendedor desempenha diferentes papéis na empresa, rotineiramente assumindo atividades operacionais e de apoio na organização. Além da burocracia, Vênus retrata a questão tributária também como prejudicial para o investimento em pequenos negócios no país e que, diante destas dificuldades, parte dos empreendedores encerra suas atividades.

Apesar de Marte afirmar que existem ações governamentais que facilitam os processos para emissão de notas fiscais eletrônicas, como a criação de aplicativo para smartphones, a atividade ainda é muito burocrática, e que mesmo podendo emitir em qualquer lugar "[...] faço a nota, demorado e tudo [...] chega na hora de emitir, não emite". Para o participante a burocracia para a emissão dos documentos fiscais não cabe na rotina do empreendedor de pequenas empresas, relatando que "[...] tem horas que eu saio da prefeitura e tá uma desgrama, você não tá com tempo, a internet também não ajuda [...] daí fica pra depois" e complementa sua fala ao afirmar que a ausência de cobrança da emissão por parte dos clientes também contribui para que as notas fiscais não sejam emitidas corretamente.

Em concordância com Forte et al. (2015) que afirmam que a prática de sonegação fiscal não deveria ser justificada pelo fator carga tributária, Júpiter afirma que não é a carga tributária incidente sobre as atividades de pequenas empresas que prejudica a arrecadação, mas sim a complexidade do atual sistema tributário.

Foi possível perceber também a insatisfação dos participantes com relação à obrigação do pagamento dos tributos e a contrapartida ofertada nos serviços públicos, o que está de acordo com o relatado por Correia e Pires (2017) que descrevem a baixa percepção de retorno social comparado aos valores arrecadados por meio do recolhimento tributário como um dos fatores utilizados como justificativa para a sonegação de tributos por parte das pequenas empresas.

Neste sentido, Urano relata que, caso o retorno social oferecido pelas instituições públicas a partir dos valores arrecadados por meio do recolhimento tributário fosse efetivo, a sonegação fiscal seria reduzida, afirmando que "[...] se fosse um sistema justo, nossa... pagaria com prazer! Pagaria imposto tranquilamente, sabe?!" e complementa sua fala, afirmando que a arrecadação também seria maior caso o empreendedor percebesse a influência positiva das instituições públicas no desenvolvimento de seus negócios.

Assim como apresentado por Urano, Marte também afirma que, caso o retorno social fosse considerado eficiente, o recolhimento tributário por parte dos pequenos negócios seria maior “[...] se fosse justo o negócio, oh, vocês tão... nós estamos comendo vocês, mas nós estamos devolvendo serviço, benefício, cara, eu pagaria com todo o prazer". Netuno acredita também que mesmo com a redução da sonegação fiscal não haveria melhoria no retorno para a população "[...] eles vão lá e roubam do mesmo jeito. Roubam do mesmo jeito e o dinheiro nunca dá [...]".

Tais fatos vão ao encontro da afirmação de Anokhin e Schulze (2009) de que os níveis de confiança dos contribuintes com relação ao Estado aumentariam a partir de uma melhoria na percepção do controle de corrupção e do retorno social.

Além desses aspectos, outro fator que parece ser utilizado para legitimar a prática de sonegação fiscal é a insuficiência de recursos próprios para o desenvolvimento da empresa, como pode ser observado na fala de Urano que "sempre tem investimento pra fazer né. Sempre queima uma lâmpada, sempre tem que trocar alguma coisa no banheiro, eu preciso inovar, eu preciso mexer lá fora, é uma tenda que compra [...]".

Seguindo o contexto de escassez de recursos como justificativa para a sonegação fiscal, a seguir aborda-se a categoria de maximização dos resultados e sobrevivência das micro e pequenas empresas. 


\section{Maximização dos rendimentos e sobrevivência da organização}

A busca pela maximização do retorno de seus investimentos pode levar o contribuinte, seja ele pessoa física ou jurídica, a agir de maneira corrupta ignorando as regras de conduta presentes na sociedade e praticando uma série de ações ilícitas (Borini \& Grisi, 2009), destacando-se a sonegação fiscal como a prática mais comum nas organizações de micro ou pequeno porte (Forte et al., 2015).

Neste sentido, Vênus relata que no seu ramo de comércio não há empresas, independente do porte, que não pratiquem atos de sonegação fiscal. Para o participante, as condições do ambiente de negócios, tornam a sonegação fiscal uma ferramenta essencial, legitimada pelos pares, para a manutenção de micro e pequenas empresas. Vênus enfatiza que "não tem ninguém que esteja aberto hoje, e eu afirmo, não tem ninguém que... pequeno, grande, dentro do meu ramo pelo menos, não tem um que não sonegue".

Ao ser questionado sobre sua percepção acerca do motivo da alta prática de sonegação fiscal, Vênus relata que "[...] é mais questão de sobrevivência", entretanto, imediatamente completa a frase afirmando que "[...] tem gente que chega num ponto que poderia pagar? Mas cara, se você tá fazendo daquele jeito, tá te sobrando X por mês, é igual eu falo... é muito fácil se acostumar com vida boa". Esse contraponto, apresentado pelo participante, representa que ações ilícitas realizadas para obter economia tributária (Correia \& Pires, 2017) nem sempre estarão atreladas à sobrevivência da organização, podendo aparecer como uma das maneiras utilizadas para maximização dos rendimentos próprios do empreendedor e de maneira intencional para mudança de qualidade de vida. Nesse ponto, Mercúrio completa que "só sobrevive, porque sonega. Se for pagar 100\%, o cara não sobrevive.".

Ao descrever as ações ilícitas realizadas para reduzir o recolhimento tributário, Júpiter relata que a compra e venda de mercadorias sem nota fiscal é uma prática muito comum: “[...] se você comprar sem nota e vender sem nota é uma forma de você [sonegar]... Lógico que você não vai fazer isso em $100 \%$ do que você faz, mas é... acontece muito, você compra uma boa quantidade sem nota e vende sem nota também".

A inviabilidade financeira em cumprir as obrigações tributárias também pode ser observada no posicionamento de Marte, segundo o qual: "[...] Infelizmente... Eu prefiro viver assim... Sobrevivendo... Certo ou errado... Não lesando ninguém. Do que 'ah, eu tô pagando tudo os impostos certinho', daí tô lá com... não consigo renovar o carro, não consigo comprar equipamento melhor [...]".

Esse trecho da entrevista de Marte reflete o conflito destacado por Forte et al. (2015, p. 97) entre "[...] ganhar mais e garantir a sobrevivência da empresa sendo antiético ou agir de forma ética e correr o risco de perder benefícios financeiros", pois, ao mesmo tempo que revela tristeza em agir de maneira ilícita, mantem sua decisão em prol da manutenção do empreendimento.

Assim como destacado por Forte et al. (2015) as falas dos entrevistados demonstram que, no entendimento dos empresários brasileiros entrevistados, a prática de sonegação fiscal é ferramenta estratégica fundamental para a sobrevivência do negócio, o que reduz a sensação de ilegalidade da prática.

\section{Fiscalização e probabilidade de punição}

De acordo com o disposto por Allingham e Sandmo (1972) que relatam que a decisão do contribuinte em realizar ou não a prática de sonegação fiscal está associada a uma escolha racional, onde pondera os riscos e as vantagens em agir ilicitamente, Mercúrio relata que suas práticas de sonegação fiscal, realizadas de maneira intencional, têm trazido maiores benefícios financeiros se comparados aos custos com punição ao longo dos vinte e cinco anos em que é proprietário de pequenos negócios. Na perspectiva do empresário: “[...] infelizmente, o crime compensa nesse país [...] custo-benefício, mesmo que cair na fiscalização, tu vai... Eles vão fazer um cálculo... Emite o que tu paga atrasado, daí de lá... pá, pá, pá... Divide em 100 vezes".

Neste sentido, as vantagens de sonegar parecem exceder os prováveis riscos, pois, a probabilidade de punição é baixa e, quando ocorre, ainda é compensatória, de acordo com o entrevistado o valor sonegado é "[...] um dinheiro que, se demorasse cinco anos, estaria aplicado. Você já tiraria o valor quase dele ali".

Por outro lado, este mesmo participante afirmou que a fiscalização, proveniente da implantação das notas fiscais eletrônicas, foi um fator determinante para a redução de suas práticas de sonegação fiscal em sua atividade de transportes: "[...] nos últimos anos eu não pude mais sonegar, porque entrou a nota fiscal eletrônica, né?!" e complementa afirmando que "hoje 
em dia tá muito fechado com essa nota fiscal eletrônica, tá muito atrelado às coisas. Tá difícil de sonegar. Então, se tiver brecha... Cada empresa sabe as brechas na sua particularidade né".

Na perspectiva de Netuno, a probabilidade de punição é considerada maior no que tange às obrigações trabalhistas, se comparada às obrigações fiscais e, esse fator, é fundamental para a decisão do empreendedor de manter em dia os recolhimentos de tributos relacionados à folha de pagamento de seus funcionários.

As afirmações de Clemente e Lírio (2017) de que o contribuinte, para tomar a decisão em sonegar, realizará uma análise dos benefícios esperados e da probabilidade de fiscalização e consequente punição, estão alinhadas com as falas de Netuno: "[...] A gente prefere muito mais andar certo na área trabalhista, do que ... a fiscalização é maior, é mais fácil de ter ... qualquer pessoa pode acionar, por exemplo, a fiscalização".

De acordo com Barth e Ognedal (2018), a detecção de baixos níveis de sonegação fiscal é mais complexa em comparação às práticas que envolvem maiores movimentações, o que reduz a probabilidade de punição nas micro e pequenas empresas. Para complementar tal discussão, o próximo tópico apresenta uma análise sobre a conscientização tributária destes indivíduos.

\section{Conscientização tributária}

Com o objetivo de proporcionar uma melhor compreensão sobre a finalidade socioeconômica dos tributos, Baialardi, Rosa e Petri (2015) descrevem que a conscientização tributária é um aspecto social que deve ser amplamente difundido entre os contribuintes, neste sentindo, parte dos empreendedores entrevistados relatou compreender, ao menos parcialmente, a importância da arrecadação tributária para a execução das políticas públicas, como é o caso de Mercúrio:

Eu vou num posto de gasolina, eu peço nota. Por quê? Porque eles já tão cobrando ali imposto meu. Então o posto de gasolina não vai me dar lá os $17 \%$ de desconto. [...] Eu ... pra produto ... pra bens e produtos, eu peço nota mesmo. Porque aquele lá, o dono do posto já tá cobrando. Não é prejudicar o dono do posto, mas ele já tá pagando. [...] Agora no serviço... no serviço a gente já faz... já é diferente. A gente... as pessoas pechincham... o serviço é o meu tempo, minha alma que foi ali no negócio. E eu não acho certo, da minha alma, meus trabalhos, dão tanto pro governo. Eu acho um absurdo.

A fala de Mercúrio demonstra que o empreendedor, embora tenha consciência de que a utilização de recursos como a educação pública é proveniente da arrecadação tributária, realizando inclusive a cobrança da nota fiscal enquanto consumidor de determinados estabelecimentos, mantém seu discurso de legitimação da própria sonegação fiscal, afirmando que a cobrança de tributos para as empresas que prestam serviços é injusta.

Ao ser questionado sobre os impactos que a sonegação fiscal traz para a sociedade, Júpiter argumenta que "[...] o que é sonegado ele não tem investimentos na saúde, na educação, transporte... É ... Basicamente você tira o dinheiro disso ai", entretanto, embora aparentemente seja consciente sobre o papel dos tributos na distribuição dos serviços públicos, busca legitimar sua prática ilícita por ter, em teoria, apoio da sociedade: "uma coisa, assim, muito interessante que é, eu tô numa área há mais de 30 anos, a gente sabe que o cliente chega aqui, ele pede o desconto pra você não emitir a nota".

Grzybovski e Hahn (2006) destacam que existe um consenso social de que o contribuinte que consegue pagar menos tributos, mesmo que isso ocorra por meios ilícitos como a sonegação, é mais inteligente que os demais contribuintes. Essa afirmação é confirmada na fala de Mercúrio:

600 reais em cima da tabela deles. Então, eu fui lá recolhi só... paguei...recolhi 70 reais, soneguei 200. E cobriu meu almoço e janta e festa. O furo...como eu digo, a lei é cheia de furo. E os... e quem é inteligente, os estudados que estuda, eles sabem tudo isso aí. A gente... o burro vai lá "não, cobrei 4 mil, recolhe 4 mil”. Não. Daí é burro né... quem não burla.

Como destacam Baialardi et al. (2015), o profissional contábil possui o importante papel de mediar essa conscientização, em decorrência de sua proximidade com os indivíduos responsáveis por decidir ou não evadir o fisco, por outra perspectiva, como Mercúrio destaca, que no início de seu empreendimento, há mais de 25 anos, recebeu a orientação de um contador para que promovesse a formalização da sua empresa apenas diante da execução de fiscalizações, isto é, o agente responsável por mediar o processo de conscientização tributária, na verdade, mediou a prática de sonegação. 


\section{Jeitinho brasileiro}

Forte et al. (2015) apontam que, quando as práticas corruptas são comuns a tal ponto de serem consideradas institucionalizadas em determinada sociedade, a população tende a desenvolver culturalmente um sentimento de prejuízo diante do sistema político. Por acreditarem estar constantemente sendo prejudicados, os contribuintes passam então a desenvolver ações visando contornar aquelas situações que julgam adversas, obtendo recompensas.

No Brasil, de acordo com Duarte (2006) esse mecanismo social utilizado como estratégia na solução de problemas é conhecido como jeitinho brasileiro e, como aponta Barbosa (2005, p. 41) pode envolver a burla de regras ou normas, assim como, pode ocorrer por meio de "conciliação, esperteza ou habilidade".

Ao ser questionado sobre os impactos da fiscalização no controle da sonegação fiscal, Marte argumenta que embora acredite que a fiscalização contribuiria para a redução dos atos ilícitos, afirma que a questão cultural no país ainda induziria o contribuinte a buscar maneiras de burlar as regras estabelecidas e fatores culturais.

De acordo com Vieira et al. (1982), o jeitinho brasileiro pode ser utilizado para contornar dificuldades que surgem no cotidiano e envolve, inclusive, ações para fugir da burocracia e burlar a fiscalização.

Neste contexto, Vênus revela que pretende encerrar as atividades de sua empresa que possui boa avaliação de crédito como uma estratégia para encerrar as atuais dívidas.

A ideia é talvez, é dar baixa dessa empresa de 20 anos, que o score é bom [...] e começar do zero, justamente pra tentar fugir dessa fiscalização, sabe? Tipo assim, "ah não, essa empresa faliu". Já que eu tô com um protesto no nome, pra justificar em teoria isso... Até tenho que falar pra minha contadora... Pra eu chegar e falar "Oh, faliu. Veja aí pra negociar com meus fornecedores", É... e daí eu abrir uma nova empresa, de alguma outra forma e começar do zero.

A fala de Vênus demonstra que o empreendedor, ao visualizar situações adversas na condução de suas atividades, busca desenvolver estratégias para contorná-las, mesmo que isso envolva a quebra de regras de conduta ou legais, como é o caso do acionamento de falência, a fim de obter melhores condições de negociação com os fornecedores, mesmo que, na prática, a empresa permaneça ativa.

Como descrito anteriormente, os empreendedores de micro e pequenas empresas apontam o sistema tributário, e a política no geral, como o principal fator adverso presente no ambiente de negócios. Assim, considerando que o jeitinho, conforme descrevem Braga e Bezerra (2017), pode refletir a transgressão de condutas sociais e de leis, é possível afirmar que a sonegação fiscal é utilizada como um jeitinho brasileiro de contornar parte das dificuldades na manutenção de micro e pequenas empresas, isto é, a prática de sonegação fiscal realizada sem viés de ilegalidade é realizada pela influência de traços culturais dos empreendedores.

Urano manifestou sua insatisfação com o sistema público e descreveu que, no início de suas atividades, encontrou dificuldades junto à prefeitura para a liberação do alvará de funcionamento, precisando recorrer à alternativa para contornar a adversidade. De acordo com o entrevistado:

[...] tivemos uma visita da prefeitura que nos apontou milhões de coisa. Eu falei "Mas gente, poxa, isso é uma loja de cerveja, não é uma indústria". Queria que eu fizesse milhões de coisas aqui, que eu falei "olha, não tem nem cabimento o que vocês tão me pedindo". Aí tivemos que entrar, através de um vereador... tem que saber usar também o meio político pra que a gente possa ter o respaldo deles.

A fala de Urano deixa claro que, a partir de um sentimento de prejuízo perante o sistema político, utilizou sua relação com terceiros (contato com o vereador) para fugir da burocracia inicialmente imposta, essa situação, de acordo com a pesquisa de Vieira et al. (1982) pode ser considerada um jeitinho brasileiro. Ao final da entrevista, a pesquisadora questionou o entrevistado sobre seu entendimento acerca do conceito de jeitinho brasileiro e Urano prontamente retomou o assunto: 
Eu acho horrível o "jeitinho brasileiro". Mas de vez em quando a gente precisa, né?! É... Às vezes a gente não se escapa. Mesmo. De verdade. Por mais que a gente queira "não, cara oh... seguinte" [...] não queria ser repetitivo, mas voltando aqui a questão do pessoal veio aqui me indagar. Eu tive que usar do "jeitinho brasileiro" pra falar assim "não, eu conheço fulano, ciclano, beltrano. Já tô lá em contato e é o seguinte". Então... não é que é o jeitinho, mas você tem que usar também as vezes alguns artifícios pra que você consiga ser respeitado, entendeu? Pra que você consiga se posicionar. É... esse é um dos jeitinhos brasileiros que a gente tem que às vezes crescer, se prevalecer em alguma situação, se não eles te esmagam também, né.

Considerando as características positivas e negativas do jeitinho brasileiro, Pedroso et al. (2009) apontam que estas podem ser aproximadas às características atribuídas ao perfil empreendedor e as opiniões dos empreendedores demonstram que, mesmo entendendo que podem ser prejudiciais e ilegais, acreditam que é preciso assumir esse comportamento.

\section{CONSIDERAÇÕES FINAIS}

O presente estudo teve como objetivo compreender como se manifesta o misbehavior de empreendedores associado às práticas de sonegação fiscal em micro e pequenas empresas sob a ótica do jeitinho brasileiro e obteve resultados que indicam diferentes fatores que influenciam as práticas de sonegação fiscal enquanto um mau comportamento empreendedor.

Dentre os fatores apontados pelos proprietários de pequenos negócios como prejudiciais para o desenvolvimento de suas empresas, a carga tributária e a burocracia do sistema recebem destaque. Para os entrevistados, o retorno social proporcionado pelo Estado não é suficiente em comparação à carga tributária aplicada nas atividades empresariais ou ao próprio consumidor final, este fato parece contribuir para a construção de falas que legitimam o ato ilícito de sonegar enquanto uma reparação da injustiça percebida do sistema tributário.

Os empreendedores também apresentam outras justificativas para legitimar a prática ilícita: a complexidade do sistema fiscal, a burocracia e a escassez de recursos para o desenvolvimento das atividades empresariais. Ao encontrarem dificuldades burocráticas para a realização de determinada atividade, os entrevistados buscam outros meios, incluindo ilícitos, para a obtenção do resultado pretendido.

Os resultados da pesquisa indicam que a sonegação fiscal, enquanto ato ilícito realizado com a intenção de anular ou reduzir a arrecadação tributária, é uma amplamente adotada como mecanismo de sobrevivência dos pequenos negócios. Os empreendedores buscam legitimar suas práticas afirmando que, caso cumprissem com suas obrigações tributárias, não teriam recursos suficientes para a manutenção ou desenvolvimento da empresa. A sensação de ilegalidade da prática acaba sendo reduzida pelo entendimento, por parte dos agentes, de que não há outro caminho para a manutenção da entidade. Neste sentido, requer atenção o fato destes empresários optarem pela sonegação fiscal em detrimento da elaboração de um planejamento financeiro e tributário.

A sonegação fiscal é, portanto, uma escolha racional do empreendedor. Embora alguns empresários tenham apresentado certa hesitação para confirmar a prática ilícita, a maior parte dos entrevistados afirmou que, ao ponderar os riscos e benefícios, o ato de sonegar é vantajoso ao pequeno negócio, uma vez que os custos com penalidades são irrisórios, considerando a baixa fiscalização e consequente probabilidade de punição.

Os empreendedores parecem compreender parcialmente a importância da arrecadação tributária para a execução de políticas públicas. Enquanto no papel de consumidores, exigem emissão de nota fiscal nos estabelecimentos que frequentam, a fim de garantir a execução da arrecadação, quando estão no papel de empresários, buscam inúmeros meios para reduzir suas obrigações tributárias, comprando e vendendo sem nota fiscal, mantendo funcionários sem o devido registro trabalhista, abrindo negócios informais, entre outros fatos. 
Embora entendam que, é a partir da arrecadação tributária que os serviços públicos podem ser disponibilizados à população, os empreendedores, ao evadir o fisco para obter recursos para o desenvolvimento de seus negócios, priorizam suas demandas individuais em prejuízo do coletivo. Para os entrevistados, embora a sonegação fiscal impacte negativamente na distribuição de recursos públicos, ao comprar de estabelecimentos informais ou não solicitar nota fiscal para obtenção de descontos, parte da própria população contribui para que a prática ilícita seja perpetuada.

Ao assumir que a sonegação fiscal, enquanto prática ilícita associada à corrupção, tem raízes históricas, entende-se que há, culturalmente, um sentimento de constante prejuízo diante do sistema político e, por consequência, do sistema tributário nacional, conforme apontam os resultados encontrados nas entrevistas. Os empreendedores relatam que utilizam de práticas, por vezes ilícitas como é o caso da sonegação fiscal, para contornar as adversidades que surgem no cotidiano empresarial, o que pode ser caracterizado como jeitinho brasileiro.

Neste contexto, a pesquisa permitiu identificar que a sonegação fiscal, na medida que acontece intencionalmente, a partir da análise racional entre riscos e benefícios, e resulta na quebra de regras legais ou morais para a obtenção de benefícios, pode ser considerada uma prática de misbehavior empreendedor. Este misbehavior, por sua vez, se manifesta como jeitinho brasileiro, uma vez que é uma prática transgressora utilizada para contornar adversidades e procura sempre ser justificada diante da sensação de injustiça do sistema público.

Os resultados alcançados destacam aspectos importantes sobre a prática do misbehavior por empreendedores de micro e pequenas empresas, entretanto, é preciso estar atento às limitações que a pesquisa apresenta. Embora as pesquisas qualitativas não utilizem critérios numéricos para obter representatividade, este estudo contou com a participação de seis entrevistados que atuam em segmentos mercadológicos distintos, o que pode ser considerado um fator limitante para se alcançar um aprofundamento no diálogo entre as categorias de análise. Além disso, ao adotar uma posição de pesquisa por acessibilidade aos empreendedores, o estudo pode não ter alcançado agentes com práticas significativas para o contexto da pesquisa.

A partir dessas limitações, mas com objetivo de aprofundar as discussões sobre o tema, recomenda-se manter a abordagem qualitativa de pesquisa, a fim de expandir os diálogos e contradições entre diferentes sujeitos, utilizando a técnica de análise de discurso, relevante para esse fim. Neste sentido, novos estudos nesta temática poderiam abordar a prática de evasão fiscal por empreendedores de micro e pequenas empresas a partir da perspectiva de diferentes atores que tenham interesse na questão da arrecadação tributária, tais como: agentes responsáveis pelos órgãos de fiscalização e controle tributário, assim como, membros da sociedade que percebem benefícios ou prejuízos diante dos recursos públicos distribuídos.

Outra possibilidade de investigação que poderia avançar no tema, se relaciona à investigação de setores específicos como construção civil, salões de beleza, comércio de vestuário ou empresas em destaque entre estudiosos de empreendedorismo, como negócios de base tecnológica, startups, empresas incubadas, entre outros. Desta forma, seria possível iniciar uma construção mais ampla de como estas práticas se manifestam em diferentes segmentos e tipos de empresas. 


\section{REFERÊNCIAS}

Allingham, M. G., \& Sandmo, A. (1972). Income tax evasion: a theoretical analysis. Journal of Public Economics, 1, 323-338. Recuperado de https://doi.org/10.1016/0047-2727(72)90010-2

Amaral, G. L., Olenike, J. E., Amaral, L. M. F., \& Steinbruch, F. (2009). Estudo sobre Sonegação Fiscal das empresas Brasileiras. Curitiba, PR: Instituto Brasileiro de Planejamento Tributário. Recuperado de https://ibpt.com.br/sonegacao-fiscal-da-empresas/

Anokhin, S., \& Schulze, W. (2009). Entrepreneurship, innovation and corruption. Journal of Business Venturing, 24, 465-476. Recuperado de https://doi.org/10.1016/j.jbusvent.2008.06.001

Baialardi, C. F., Rosa, P. A., \& Petri, S. M. (2015). O contador como colaborador da conscientização tributária. Revista Ambiente Contábil, 7(1), 1-17. Recuperado de https://periodicos.ufrn.br/ambiente/ article/view/5029/5056

Barbosa, L. (2005). O jeitinho brasileiro: a arte de ser mais igual do que os outros. Rio de Janeiro, RJ: Elsevier.

Barth, E., \& Ognedal, T. (2018). Tax Evasion in Firms. Labour, 32(1), 23-44. Recuperado de https://doi.org/10.1007/978-1-4614-7753-2_34

Berger, F. S., Dallapicula, T. M., Alencar, R. C., \& Dalmácio, F. Z. (2009). A ética da evasão fiscal: um estudo comparativo de profissionais e estudantes da área de negócios. In Anais do 3 International Accounting Congress, São Paulo, SP.

Borini, F. M., \& Grisi, F. C. (2009). A corrupção no ambiente de negócios: survey com as micro e pequenas empresas da cidade de São Paulo. Revista de Administração, 44(2), 102-117. Recuperado de http://200.232.30.99/download.asp?file=V4402102.pdf

Braga, S. P., \& Bezerra, E. V. (2017). O jeitinho brasileiro: as pequenas corrupções diárias e seus reflexos na morosidade da justiça. Revista de Política Judiciária, Gestão e Administração da Justiça, 3(1), 17-33. Recuperado de http://dx.doi.org/10.26668/ IndexLawJournals/2525-9822/2017.v3i1.2160

Brenkert, G. G. (2009). Innovation, rule breaking and the ethics of entrepreneurship. Journal of Business Venturing, 24(5), 448-464. Recuperado de https://doi.org/10.1016/j.jbusvent.2008.04.004

Casson, M. C. (2000). An entrepreneurial theory of the firm. In N. J. Foss, \& V. Mahnke (Eds.), Competence, governance and entrepreneurship: advances in economic strategy research (1a ed., Cap. 6, pp. 116-145). Oxford, UK: Oxford University Press.

Clemente, F., \& Lírio, V. S. (2017). Evidências internacionais de sonegação fiscal: uma análise a partir do modelo de Graetz, Reinganun e Wilde. Estudos Econômicos, 47(3), 487-507. Recuperado de https:// doi.org/10.1590/0101-41614732fcv

Collinson, D. L., \& Ackroyd, S. (2005). Resistance, misbehavior and dissent. In R. Batt, P. Thompson, \& P. S. Tolbert (Eds.), The Oxford handbook of work \& organization. Oxford, UK: Oxford University Press.

Correia, P. M. A. R., \& Pires, I. C. G. M. (2017). Evasão fiscal, ética e controvérsias: percepções do agente fiscal sobre a ética fiscal dos contribuintes. Revista Estudo \& Debate, 24(2), 230-248. Recuperado de http://dx.doi.org/10.22410/issn.1983-036X.v24i2a2017.1324
Costa, R. E. (2018). Organizational Misbehavior: explorando experiências em instituições públicas de ensino superior do Triângulo Mineiro e Sul Goiano (Dissertação de Mestrado). Universidade Federal de Uberlândia, Uberlândia, MG.

Duarte, F. (2006). Exploring the Interpersonal Transaction of the Brazilian Jeitinho in Bureaucratic Contexts. Organization, 13(4), 509527. Recuperado de https://doi.org/10.1177/1350508406065103

Eckhardt, J. T., \& Shane, S. A. (2003). Opportunitties and entrepreneurship. Journal of Management, 29(3), 333-349. Recuperado de https://doi.org/10.1016/S0149-2063(02)00225-8

Eslabão, D. R., \& Vecchio, F. B. (2016). Condições e Obstáculos ao Empreendedorismo no Brasil. Revista de Economia, Empresas e Empreendedores na CPLP, 2, 79-90. Recuperado de https://doi. org/10.29073/e3.v2i2.22

Flach, L. (2012). O jeitinho brasileiro: analisando suas características e influências nas práticas organizacionais. Gestão e Planejamento, 13(3), 499-514. Recuperado de https://revistas.unifacs.br/index. $\mathrm{php} / \mathrm{rgb} /$ article/view/1197/1852

Forte, S. H. A. C., Domingues, M. C. S., \& Oliveira, O. V. (2015). Uso e percepção de licitude de práticas ilegais ou antiéticas de sobrevivência de micro e pequenas empresas. Revista Ibero-Americana de Estratégia, 14(3), 93-109. Recuperado de https://doi.org/10.5585/ijsm.v14i3.2203

Gervásio, V. S. O. S. (2018). Compreendendo o organizational misbehaviour na gestão pública: um estudo de caso em uma instituição de ensino superior pública (Dissertação de Mestrado). Universidade Federal de Uberlândia, Uberlândia, MG.

Godoi, C. K., Bandeira-De-Mello, R., \& Silva, A. B. (2006). Pesquisa Qualitativa em Estudos Organizacionais: Paradigmas, Estratégias e Métodos. São Paulo, SP: Saraiva.

Griffin, R. W., \& Lopez, Y. P. (2005). "Bad behavior" in organizations: A review and typology for future research. Journal of Management, 31(6), 988-1005. Recuperado de https://doi.org/10.1177/0149206305279942

Grzybovski, D., \& Hahn, T. G. (2006). Educação fiscal: premissa para melhor percepção da questão tributária. Revista de Administração Pública, 40(5), 841-864. Recuperado de https://doi.org/10.1590/ S0034-76122006000500005

Hisrich, R. D., Peters, M. P., \& Shepherd, D. A. (2014). Empreendedorismo (9a ed.). Porto Alegre, RS: AMGH.

Lima, B. R. T., Wilbert, M. D., \& Serrano, A. L. M. (2017). Parcelamento de Tributos Federais como Forma de Financiamento Indireto. Revista de Administração, Contabilidade e Economia, 16(3), 1079-1108. Recuperado de https://doi.org/10.18593/race.v16i3.13405

Medeiros, C. R. O., \& Alcadipani, R. (2016). In the corporate backstage, the taste of revenge: misbehaviour and humor as form of resistance and subversion. Revista Administração, 51(2), 123-136. Recuperado de https://doi.org/10.5700/rausp1229

Menezes, Á., Wilbert, M., \& Lima, B. (2017, dezembro). Probabilidade de Detecção de Evasão Fiscal: uma análise da evolução da fiscalização da pessoa jurídica no período de 2006 a 2016. In Anais do 3o Congresso UnB de Contabilidade e Governança, Brasília, DF. 
Motta, F. C. P., \& Alcadipani, R. (1999). Jeitinho brasileiro, controle social e competição. Revista de Administração de Empresas, 39(1), 6-12. Recuperado de https://www.scielo.br/pdf/rae/v39n1/ v39n1a02.pdf

Pedroso, J. P. P., Massukado-Nakatani, M. S., \& Mussi, F. B. (2009). A relação entre o jeitinho brasileiro e o perfil empreendedor: possíveis interfaces no contexto da atividade empreendedora no Brasil. Revista de Administração Mackenzie, 10(4), 100-130. Recuperado de https:// doi.org/10.1590/S1678-69712009000400006.

Robinson, S. L., \& Bennett, R. J. (1995). A typology of deviant workplace behaviors: amultidimensional scaling study. Academy of Management Journal, 38(2), 555-572.

Serviço de Apoio às Micro e Pequenas Empresas. (2018). Conheça os principais números sobre a participação dos pequenos negócios nas economias brasileira e paulista. Recuperado de http://www.sebrae. com.br/sites/PortalSebrae/ufs/ro/artigos/perfil-das-microempresase-empresas-de-pequeno-porte-2018,a2fb479851b33610VgnVCM10 00004c00210aRCRD

Shane, S., \& Venkataraman, S. (2000). The promise of entrepreneurship as a field of research, Academy of Management. The Academy of
Management Review, 25(1), 217-226. Recuperado de https://doi. org/10.2307/259271

Sindicato Nacional dos Procuradores da Fazenda Nacional. (2019). Reportagem cita sonegômetro, placar da sonegação criado pelo SINPROFAZ. Recuperado de https://www.sinprofaz.org.br/ noticias/reportagem-cita-sonegometro-placar-da-sonegacao-criado-pelo sinprofaz/

Siqueira, M. L., \& Ramos, F. S. (2005). A economia da sonegação: teorias e evidências empíricas. Revista de Economia Contemporânea, 9(3), 555-581. Recuperado de https://doi.org/10.1590/\$1415- 984820050003 00004

Vardi, Y., \& Weitz, E. (2004). Misbehaviour in Organisations: Theory, Research and Management. Mahwah, NJ: LEA.

Vardi, Y., \& Wiener, Y. (1996). Misbehavior in organizations: A motivational framework. Organization Science, 7(2), 151-165. Recuperado de https://www.jstor.org/stable/2634978

Vieira, C. A., Costa, F. L., \& Barbosa, L. O. (1982). O "jeitinho” brasileiro como um recurso de poder. Revista de Administração Pública, 16(1), 5-31. Recuperado de http://bibliotecadigital.fgv.br/ojs/index.php/ rap/article/view/11440/10392

Marina Emanuelli Belo

ORCID: https://orcid.org/0000-0002-7263-8922

Mestra em Administração pelo Departamento Acadêmico de Gestão e Economia da Universidade Tecnológica Federal do Paraná (UTFPR)

E-mail: marinaebelo@gmail.com

Thiago Cavalcante Nascimento ORCID: https://orcid.org/0000-0002-5452-8965

Doutor em Administração pela Universidade Federal do Paraná (UFPR); Professor do Programa de Pós-Graduação em Administração da Universidade Tecnológica Federal do Paraná (UTFPR). E-mail: thiagocn1@hotmail.com

Andréa Torres Barros Batinga de Mendonça ORCID: https://orcid.org/0000-0002-9585-7239

Doutora em Administração pela Universidade Federal do Paraná (UFPR); Professora do Programa de Pós-Graduação em Gestão da Informação da Universidade Federal do Paraná (UFPR). E-mail: andrea.tbbm@gmail.com 